\title{
Methods for Investigating the Larval Period and Metamorphosis in Xenopus
}

\author{
Daniel R. Buchholz ${ }^{1,3}$ and Yun-Bo Shi ${ }^{2,3}$ \\ ${ }^{1}$ Department of Biological Sciences, University of Cincinnati, Cincinnati, Ohio 45244; ${ }^{2}$ Section on Molecular \\ Morphogenesis, Eunice Kennedy Shriver National Institute of Child Health and Human Development (NICHD), \\ National Institutes of Health (NIH), Bethesda, Maryland 20892
}

\begin{abstract}
Anuran metamorphosis resembles postembryonic development in mammals, a period around birth when many organs/tissues mature into their adult form as circulating thyroid and stress hormone levels are high. Unlike uterus-enclosed mammalian embryos, tadpoles develop externally and undergo the dramatic changes of hormone-dependent development totally independent of maternal influence, making them a valuable model in which to study vertebrate postembryonic organ development and maturation. Various protocols have been developed and/or adapted for studying metamorphosis in Xenopus laevis and X. tropicalis, two highly related and well-studied frog species. Here, we introduce some of the methods for contemporary cell and molecular studies of gene function and regulation during metamorphosis.
\end{abstract}

Amphibians undergo a biphasic development process (Dodd and Dodd 1976; Shi 1999). Their embryogenesis leads to the formation of free-feeding tadpoles, which after a finite period of growth undergo the second phase of development, metamorphosis. Metamorphosis in anurans (frogs and toads) is the most dramatic among amphibians, with essentially every organ/tissue changing drastically by the end of metamorphosis. While two dramatic phases of development exist only in amphibians among terrestrial vertebrates, all vertebrates undergo similar developmental processes (Tata 1993; Laudet 2011; Buchholz 2015). In mammals, the initial embryonic development leads to the formation of most organs. After a period of growth and enlargement, the organs then mature into the adult forms. This second period of development occurs around birth in mammals. While much has been learned about early embryonic development by using various vertebrate models, much less is known about postembryonic development, especially in mammals. This is largely because of the difficulty of manipulating and analyzing uterus-enclosed late-stage mammalian embryos and neonates, which are still dependent on the maternal supply of nutrients for survival.

A key aspect of postembryonic development is the peak in plasma thyroid hormone (TH) around birth, hatching and metamorphosis, which are equivalent periods in different animal species (Sachs and Buchholz 2017). Although birth still occurs in mammals in the absence of TH, many organ systems are abnormal, especially neural development (Hetzel 1989; Braverman and Utiger 2005).

${ }^{3}$ Correspondence: buchhodr@ucmail.uc.edu; Shi@helix.nih.gov

From the Xenopus collection, edited by Hazel L. Sive.

(C) 2018 Cold Spring Harbor Laboratory Press

Cite this introduction as Cold Spring Harb Protoc; doi:10.1101/pdb.top097667 
In frog metamorphosis, the role of TH is more significant, as TH signaling is necessary and sufficient for most developmental events that occur during metamorphosis (Dodd and Dodd 1976; Shi 1999). It is easy to block metamorphosis completely by inhibiting endogenous TH synthesis or to induce metamorphosis precociously by adding physiological levels of TH to the rearing water of premetamorphic tadpoles (Dodd and Dodd 1976; Shi 1999). Other factors (such as environmental rearing conditions or other hormones, including stress hormone) affect metamorphic events (Denver 2009; Denver et al. 2009); however, these factors influence metamorphosis mostly indirectly through their effects on TH signaling (Bonett et al. 2010). The dramatic TH-dependent changes and ease of experimental manipulation have made anuran metamorphosis a unique and valuable model for studying postembryonic development in vertebrates (Sachs and Buchholz 2017). Over the last few decades, two highly related anuran species, the allo-tetraploid Xenopus laevis and the diploid $X$. tropicalis, have been studied extensively for various aspects of metamorphosis (Furlow and Neff 2006; Brown and Cai 2007; Das et al. 2010; Sachs and Buchholz 2017). The methods introduced here focus on some of the techniques that are employed in contemporary cell and molecular studies of gene regulation and functions during metamorphosis. Many other protocols, including those for gene expression, transgenesis, and gene editing, can also be used for metamorphosis studies.

\section{ANALYSIS OF GENE REGULATION AND FUNCTION DURING METAMORPHOSIS}

All vertebrates experience a period of preadult development controlled by hormones; in mammals, this development occurs inside the uterus (Sachs and Buchholz 2017). Frog metamorphosis provides a valuable research model in which to study this developmental period because hormone-dependent developmental progression occurs in free-living tadpoles to a dramatic and easily manipulable degree. Frog metamorphosis has provided an in vivo testing ground for molecular mechanisms of gene regulation proposed based on cell culture studies, from thyroid hormone receptor function (Shi 2009) and natural and synthetic thyroid hormone receptor agonists and antagonists (Lim et al. 2002; Schriks et al. 2007) to chromatin remodeling (Wong et al. 1995), cofactor recruitment (Shi 2013) and long-range hormone-DNA interactions (Buisine et al. 2015).

The protocols introduced here represent fundamental and recent approaches to answering outstanding questions about the roles of genes in development in different tissues, the actions of thyroid hormone and its interactions with other hormones during development, and the molecular and genetic mechanisms underlying postembryonic developmental processes. These protocols range from general purpose procedures (tissue harvest, cell proliferation) to specific manipulations in specific tissues (transfections of brain and tail, intestine organ culture, and ChIA-PET from tail skin) (Fig. 1). Protocol: Xenopus Tadpole Tissue Harvest (Patmann et al. 2017) will apply to a great number of experiments performed on tadpoles. Tadpoles are large enough to harvest nearly all tissues from single individuals to assess morphological, histological, and transcriptional responses to thyroid hormone. Other experiments require a large volume of starting material. In either case, the descriptions and images provided in Protocol: Xenopus Tadpole Tissue Harvest (Patmann et al. 2017) represent, for researchers new to tadpole anatomy, a fundamental step in experimental procedures on frog metamorphosis. Protocol: Cell Proliferation Analysis During Xenopus Metamorphosis: Using 5Ethynyl-2-Deoxyuridine (EdU) to Stain Proliferating Intestinal Cells (Okada and Shi 2017) is another widely applicable method, as cell proliferation plays a prominent role in many tissues during postembryonic developmental remodeling.

A valuable aspect of studying frog metamorphosis is that many organs, including tail, limb, lung, liver, and skin, can be cultured in vitro, thereby providing stringent experimental control over developmental changes that mimic what happens in the whole organism. Protocol: Organ Culture of the Xenopus Tadpole Intestine (Ishizuya-Oka 2017) describes procedures for studying the effects of hormones on intestinal remodeling and the developmental origin of stem cells in vitro; the basic procedures detailed in that protocol will apply to other tadpole organs as well. Studying gene function 


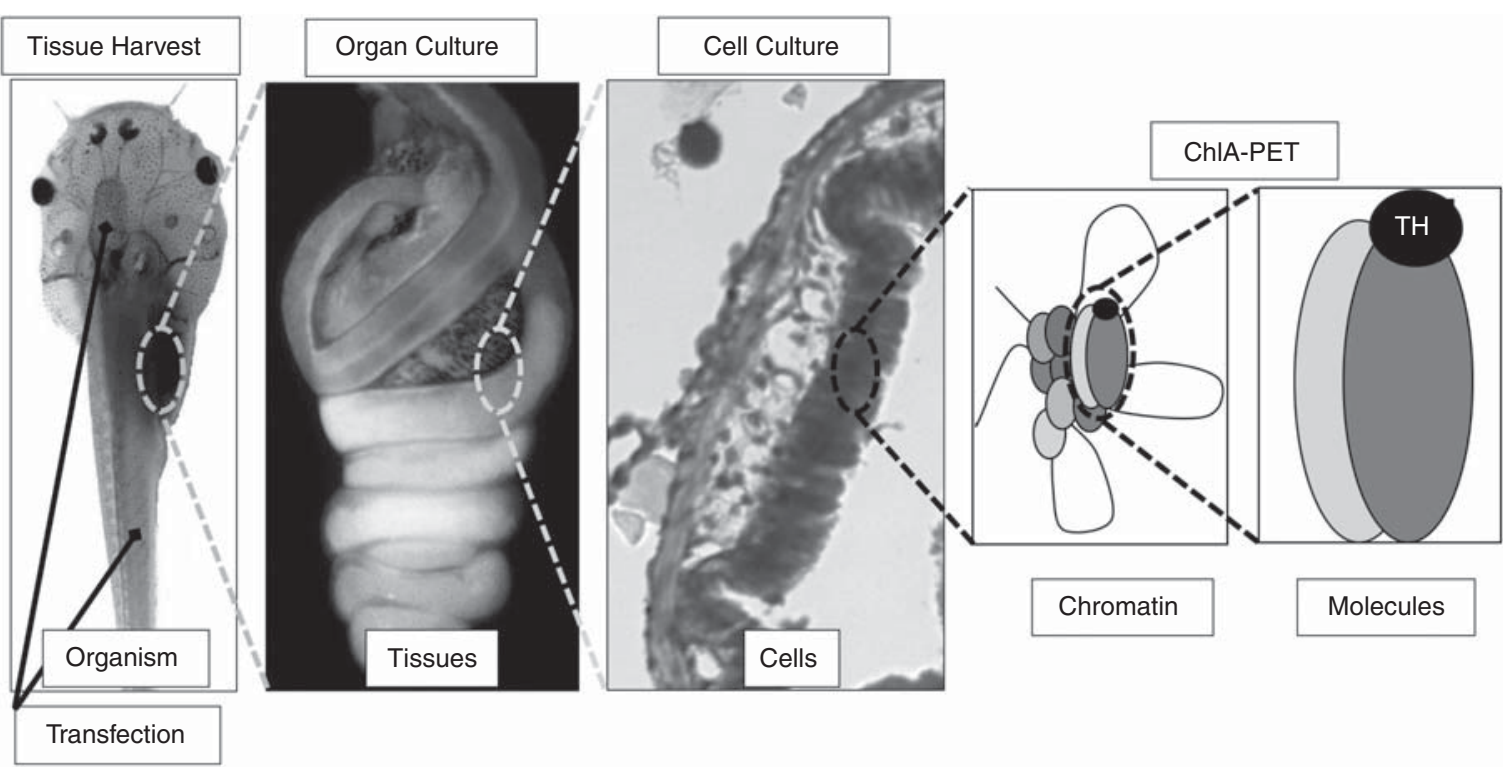

FIGURE 1. Levels of analysis of the Xenopus model to elucidate mechanisms of hormonal control of development. From left to right, the figure panels show decreasing biological levels from organism (tadpole) to tissues (whole intestine), cells (intestinal cross-section), chromatin structure (chromosomal looping) and molecules (receptorhormone interaction, thyroid hormone [TH] bound to its nuclear receptor). The focal biological levels queried by the protocols introduced here are indicated. For tissue harvest, see Protocol: Xenopus Tadpole Tissue Harvest (Patmann et al. 2017); for transfection, see Protocol: Bulk Electroporation-Mediated Gene Transfer into Xenopus Tadpole Brain (Sáenz de Miera et al. 2018) and Protocol: In Vivo Transfection of Naked DNA into Xenopus Tadpole Tail Muscle (Marshall et al. 2017); for organ culture, see Protocol: Organ Culture of the Xenopus Tadpole Intestine (Ishizuya-Oka 2017); for cell culture, see Protocol: Cell Proliferation Analysis During Xenopus Metamorphosis: Using 5-Ethynyl-2-Deoxyuridine (EdU) to Stain Proliferating Intestinal Cells (Okada and Shi 2017); for ChIA-PET, see Protocol: Chromatin Immunoprecipitation for Chromatin Interaction Analysis Using Paired-End-Tag (ChIAPET) Sequencing in Tadpole Tissues (Buisine et al. 2018a) and Protocol: Chromatin Interaction Analysis Using Paired-End-Tag (ChIA-PET) Sequencing in Tadpole Tissues (Buisine et al. 2018b).

in mammals often involves genetically modified lines. However, Protocol: Bulk ElectroporationMediated Gene Transfer into Xenopus Tadpole Brain (Sáenz de Miera et al. 2018) and Protocol: In Vivo Transfection of Naked DNA into Xenopus Tadpole Tail Muscle (Marshall et al. 2017) open the door to rapid and targeted studies of gene function, thus bypassing the requirement for lengthy and laborious characterization of genetically modified lines. A central, contemporary question in gene regulation concerns chromatin conformation, transcription factor binding, and the location and role of enhancers in transcription initiation. Protocol: Chromatin Immunoprecipitation for Chromatin Interaction Analysis Using Paired-End-Tag (ChIA-PET) Sequencing in Tadpole Tissues (Buisine et al. 2018a) and Protocol: Chromatin Interaction Analysis Using Paired-End-Tag (ChIA-PET) Sequencing in Tadpole Tissues (Buisine et al. 2018b) describe methods central to addressing this question by detailing how to identify functional chromatin interactions genome-wide between binding sites of a transcription factor and the promoters of genes regulated by that transcription factor.

\section{ACKNOWLEDGMENTS}

Y.-B.S. was supported by the Intramural Research Program of the National Institute of Child Health and Human Development, National Institutes of Health. 


\section{REFERENCES}

Bonett RM, Hoopfer ED, Denver RJ. 2010. Molecular mechanisms of corticosteroid synergy with thyroid hormone during tadpole metamorphosis. Gen Comp Endocrinol 168: 209-219.

Braverman LE, Utiger RD (eds.). 2005. Werner and Ingbar's the thyroid. Lippincott, Williams, and Wilkins, Philadelphia.

Brown DD, Cai L. 2007. Amphibian metamorphosis. Dev Biol 306: 20-33.

Buchholz DR. 2015. More similar than you think: Frog metamorphosis as a model of human perinatal endocrinology. Dev Biol 408: 188-195.

Buisine N, Ruan X, Bilesimo P, Grimaldi A, Alfama G, Ariyaratne P, Mulawadi F, Chen J, Sung WK, Liu ET, et al. 2015. Xenopus tropicalis genome re-scaffolding and re-annotation reach the resolution required for in vivo ChIA-PET analysis. PLoS One 10: e0137526.

Buisine N, Ruan X, Ruan Y, Sachs LM. 2018a. Chromatin immunoprecipitation for chromatin interaction analysis using paired-end-tag (ChIAPET) sequencing in tadpole tissues. Cold Spring Harb Protoc doi: 10.1101/pdb.prot097725.

Buisine N, Ruan X, Ruan Y, Sachs LM. 2018b. Chromatin interaction analysis using paired-end-tag (ChIA-PET) sequencing in tadpole tissues. Cold Spring Harb Protoc doi: 10.1101/pdb.prot104620.

Das B, Matsuda H, Fujimoto K, Sun G, Matsuura K, Shi YB. 2010. Molecular and genetic studies suggest that thyroid hormone receptor is both necessary and sufficient to mediate the developmental effects of thyroid hormone. Gen Comp Endocrinol 168: 174-180.

Denver RJ. 2009. Stress hormones mediate environment-genotype interactions during amphibian development. Gen Comp Endocrinol 164: $20-31$.

Denver RJ, Glennemeier KA, Boorse GC. 2009. Endocrinology of complex life cycles: Amphibians. In Hormones, brain and behavior, 2nd ed. (ed. Pfaff DW, et al.), pp. 707-744. Academic Press, San Diego.

$\div$ Dodd MHI, Dodd JM. 1976. The biology of metamorphosis. In Physiology of the Amphibia (ed. Lofts B), pp. 467-599. Academic Press, New York.

Furlow JD, Neff ES. 2006. A developmental switch induced by thyroid hormone: Xenopus laevis metamorphosis. Trends Endocrinol Metab 17: 40-47.

Hetzel BS. 1989. The story of iodine deficiency: An international challenge in nutrition. Oxford University Press, Oxford.

Ishizuya-Oka A. 2017. Organ culture of the Xenopus tadpole intestine. Cold Spring Harb Protoc doi: 10.1101/pdb.prot097683.
Laudet V. 2011. The origins and evolution of vertebrate review metamorphosis. Curr Biol 21: R726-R737.

Lim W, Nguyen NH, Yang HY, Scanlan TS, Furlow JD. 2002. A thyroid hormone antagonist that inhibits thyroid hormone action in vivo. J Biol Chem 277: 35664-35670.

Marshall L, Girardot F, Demeneix BA, Coen L. 2017. In vivo transfection of naked DNA into Xenopus tadpole tail muscle. Cold Spring Harb Protoc doi: 10.1101/pdb.prot099366.

Okada M, Shi Y.-B. 2017. Cell proliferation analysis during Xenopus metamorphosis: Using 5-ethynyl-2-deoxyuridine (EdU) to stain proliferating intestinal cells. Cold Spring Harb Protoc doi: 10.1101/pdb. prot097717.

Patmann MD, Shewade LH, Schneider KA, Buchholz DR. 2017. Xenopus tadpole tissue harvest. Cold Spring Harb Protoc doi: 10.1101/pdb. prot097675

Sachs LM, Buchholz DR. 2017. Frogs model man: In-vivo thyroid hormone signaling during development. Genesis 55: e23000.

Sáenz de Miera C, Parr E, Denver RJ. 2018. Bulk electroporation-mediated gene transfer into Xenopus tadpole brain. Cold Spring Harb Protoc doi: 10.1101/pdb.prot097691.

Schriks M, Roessig JM, Murk AJ, Furlow JD. 2007. Thyroid hormone receptor isoform selectivity of thyroid hormone disrupting compounds quantified with an in vitro reporter gene assay. Environ Toxicol Pharmacol 23: 302-307.

Shi YB. 1999. Amphibian metamorphosis: From morphology to molecular biology. Wiley-Liss, New York.

Shi YB. 2009. Dual functions of thyroid hormone receptors in vertebrate development: The roles of histone-modifying cofactor complexes. Thyroid 19: 987-999.

Shi YB. 2013. Unliganded thyroid hormone receptor regulates metamorphic timing via the recruitment of histone deacetylase complexes. Curr Top Dev Biol 105: 275-297.

Tata JR. 1993. Gene expression during metamorphosis: An ideal model for postembryonic development. Bioessays 15: 239-248.

Wong J, Shi YB, Wolffe AP. 1995. A role for nucleosome assembly in both silencing and activation of the Xenopus TR beta A gene by the thyroid hormone receptor. Genes Dev 9: 2696-2711. 


\section{Methods for Investigating the Larval Period and Metamorphosis in Xenopus}

Daniel R. Buchholz and Yun-Bo Shi

Cold Spring Harb Protoc; doi: 10.1101/pdb.top097667 originally published online May 16, 2018

\begin{tabular}{|c|c|}
\hline $\begin{array}{r}\text { Email Alerting } \\
\text { Service }\end{array}$ & Receive free email alerts when new articles cite this article - click here. \\
\hline $\begin{array}{l}\text { Subject } \\
\text { Categories }\end{array}$ & $\begin{array}{l}\text { Browse articles on similar topics from Cold Spring Harbor Protocols. } \\
\text { Developmental Biology (728 articles) } \\
\text { DNA Delivery/Gene Transfer ( } 344 \text { articles) } \\
\text { DNA:Protein Interactions ( } 74 \text { articles) } \\
\text { Embryonic Stem Cells ( } 55 \text { articles) } \\
\text { Laboratory Organisms, general (923 articles) } \\
\text { Non-Viral Methods ( } 226 \text { articles) } \\
\text { Stem Cells ( } 46 \text { articles) } \\
\text { Xenopus ( } 210 \text { articles) }\end{array}$ \\
\hline
\end{tabular}

